\title{
VIBRONIC ORIGIN OF THE "SKEWED” ANTICLINE CONFIGURATION OF THE HYDROGEN PEROXIDE MOLECULE
}

\author{
N. N. Gorinchoy*, I. Ya. Ogurtsov and Ion Arsene \\ Institute of Chemistry, Academy of Sciences of Moldova, Academiei str. 3, MD 2028 Kishinev, Republic of Moldova \\ *E-mail:ngorinchoy@yahoo.com; Phone 37322739649
}

\begin{abstract}
The vibronic origin of instability of the symmetrical forms $\left(\mathrm{D}_{¥ \mathrm{~h}}, \mathrm{C}_{2 \mathrm{~h}}\right.$ and $\left.\mathrm{C}_{2 \mathrm{v}}\right)$ of the hydrogen peroxide molecule $\mathrm{H}_{2} \mathrm{O}_{2}$ was revealed using ab initio calculations of the electronic structure and the adiabatic potential energy curves. The vibronic constants in this approach were estimated by fitting of the ab initio calculated adiabatic potential in the vicinity of the high-symmetry nuclear configurations to its analytical expression. It was shown that the equilibrium "skewed" anticline shape of the $\mathrm{C}_{2}$ symmetry can be realized in two ways: $\mathrm{D}_{¥ \mathrm{~h}}{ }^{\circledR} \mathrm{C}_{2 \mathrm{v}}{ }^{\circledR} \mathrm{C}_{2}$ or $\mathrm{D}_{¥ \mathrm{q}}{ }^{\circledR}$ $\mathrm{C}_{2 \mathrm{~h}}{ }^{\circledR} \mathrm{C}_{2}$ with the decreasing of the adiabatic potential energy at every step.
\end{abstract}

Keywords: hydrogen peroxide, electronic structure, pseudo Jahn-Teller effect

\section{Introduction}

It is known that molecules of the type ABBA have a different geometry in gaseous phase: acetylene $\mathrm{HCCH}$ is a linear molecule $\left(\mathrm{D}_{¥ \mathrm{~h}}\right)$, HNNH has a bent form with the $\mathrm{C}_{2 \mathrm{~h}}$ symmetry and hydrogen peroxide $\mathrm{H}_{2} \mathrm{O}_{2}$ adopts a "skewed" anticline shape with $\ominus \mathrm{HOO}=94.8^{\circ}$ and dihedral angle $\mathrm{j}_{\text {ноон }}=111.5^{\circ}$ [1]. In general, the problem of molecular geometry can be determined experimentally or by numerical calculations of its equilibrium (lowest in total energy) conformation. There are many modern computer program packages that perform such geometry optimization at least for the ground state, the results being strongly dependent on the method of calculation and on the type of the used basis set. However, such studies of the molecular geometry give no physical explanation of the origin of the shape of molecule. Very often the symmetry of the nuclear configuration at the minimum is lower than the possible high-symmetry one. It was proved (see in [2]) and confirmed by numerical calculations [3-6] that the only reason of instability and distortions of highsymmetry configurations of systems in non-degenerated electronic states is the pseudo Jahn-Teller effect (PJTE).

Quantum chemical calculations of the hydrogen peroxide molecule available in literature (see, foe example, [7-9] and references therein) are devoted manly to determination of the equilibrium geometrical parameters and the barriers (cis-, trans-) to internal rotation. The analysis of the whole adiabatic potential energy surface (APES) of the $\mathrm{H}_{2} \mathrm{O}_{2}$ molecule and of the reasons causing its low-symmetry equilibrium nuclear configuration where not considered as yet.

In the present paper, distinguished from other works, we started the calculations of the hydrogen peroxide molecule from the highest possible $\mathrm{D}_{¥ \mathrm{~h}}$ symmetry, analyzed its distortion towards planar bent cis- $\left(\mathrm{C}_{2 \mathrm{v}}\right)$ and trans- $\left(\mathrm{C}_{2 \mathrm{~h}}\right)$ transition states, and then to the equilibrium "skewed" $\left(\mathrm{C}_{2}\right)$ shape, and demonstrated that at every step the distortion of the molecule, accompanied by lowering of the symmetry of the nuclear configuration, is due to the pseudo Jahn-Teller effect.

\section{General theory}

According to the PJTE theory [2] the adiabatic potential (AP) surface $\varepsilon_{0}\left(q_{\bar{\Gamma}}\right)$ in the space of small displacements $q \bar{\Gamma}($ read off from $\varepsilon=0)$ may be written as follows:

$$
\varepsilon_{0}\left(q_{\bar{\Gamma}}\right)=\frac{1}{2}\left(K_{0 \bar{\Gamma}}^{\Gamma}+K_{v \bar{\Gamma}}^{\Gamma}\right) \cdot q_{\bar{\Gamma}}^{2},
$$

where the bare (nonvibronic) force constant $K_{0 \bar{\Gamma}}^{\Gamma}$,

$$
K_{0 \bar{\Gamma}}^{\Gamma}=\left\langle\Gamma\left|\left(\partial^{2} \hat{H}\left(r, q_{\bar{\Gamma}}\right) / \partial q_{\bar{\Gamma}}^{2}\right)_{0}\right| \Gamma\right\rangle,
$$

describes the contribution of the fixed ground state electron distribution to the force constant, while the second term, $K_{v \bar{\Gamma}}^{\Gamma}$ (which is always negative), 


$$
K_{v \bar{\Gamma}}^{\Gamma}=-2 \sum_{\Gamma^{\prime}}\left|F_{\bar{\Gamma}}^{\Gamma \Gamma^{\prime}}\right|^{2} /\left(E_{\Gamma^{\prime}}-E_{\Gamma}\right) .
$$

is the vibronic coupling contribution to the curvature of the AP arising from the mixing of the ground $(\Gamma)$ with the excited $\left(\Gamma^{\prime}\right)$ states in the second order perturbation theory, and

$$
F_{\bar{\Gamma}}^{\Gamma \Gamma^{\prime}}=\left\langle\Gamma\left|\left(\partial \hat{H}\left(r, q_{\bar{\Gamma}}\right) / \partial q_{\bar{\Gamma}}\right)_{0}\right| \Gamma^{\prime}\right\rangle,
$$

is the constant of vibronic coupling between the mixing states. In eqs. (2)-(4) $\mathrm{H}$ is the electronic Hamiltonian of the system, and $\mathrm{E}_{\Gamma}$ and $\mathrm{E}_{\Gamma}{ }^{\prime}$ are the total energies of the ground and excited states respectively. Derivatives in these equations are taken in the reference configuration at $q_{\bar{\Gamma}}=0$. Note that the vibronic constants $F_{\bar{\Gamma}} \Gamma^{\prime}$, and therefore the vibronic contribution $K_{v \bar{\Gamma}}^{\Gamma}$ to the curvature of the AP, are nonzero only if $\Gamma \otimes \Gamma^{\prime}$ contains $\bar{\Gamma}$.

It was proved analytically and confirmed by a series of numerical calculations [2-6] that for any molecular system the contribution to the curvature of AP of the ground state is always positive,

$$
K_{0 \bar{\Gamma}}^{\Gamma} \geq 0
$$

This means that structural instabilities and distortions of high-symmetry configurations of any polyatomic system in non-degenerate states are due to, and only to the PJTE, the mixing of the electronic state under consideration with higher in energy (excited) states under the nuclear displacements in the direction of distortion. The instability takes

place if the inequality $\left|K_{\nu \bar{\Gamma}}^{\Gamma}\right| \geq K_{0 \bar{\Gamma}}^{\Gamma}$ holds, i.e. when the vibronic coupling is strong enough and/or the energy gap between the mixing states is relatively small. To answer the questions whether the system in the reference nuclear configuration is stable or not with respect to any low-symmetry coordinate $q_{\bar{\Gamma}}$, the wave functions, energy gaps $E_{\Gamma^{\prime}}{ }^{-}$ $E_{\Gamma}$, and the matrix elements $F_{\bar{\Gamma}}^{\Gamma \Gamma^{\prime}}$ and $K_{0 \bar{\Gamma}}^{\Gamma}$ should be calculated for the states that are mixed under the displacement under consideration.

\section{Coordinates of instability}

Investigation of the possible spatial structures of the system should be started with its highest possible symmetry. In the case of the $\mathrm{H}_{2} \mathrm{O}_{2}$ molecule the linear configuration of $\mathrm{D}_{\infty \mathrm{h}}$ symmetry is the reference one. In this configuration the four-atom molecular system $\mathrm{H}_{2} \mathrm{O}_{2}$ has seven vibrational degrees of freedom, which transform according to the irreducible representations $2 \sigma_{g}^{+}+\sigma_{u}^{+}+\pi_{g}+\pi_{u}$. Two modes, $\pi_{\mathrm{u}}$ and $\pi_{\mathrm{g}}$, correspond to the bending of the molecule and transform the linear nuclear configuration into the cis- $\left(\mathrm{C}_{2 \mathrm{v}}\right)$ and trans- $\left(\mathrm{C}_{2 \mathrm{~h}}\right)$ transition states, leaving them, however, planar. Schematic illustration of these two modes is shown in Fig.1, a,b.

After separating of the center of masses we come to the following symmetrized displacements of the $\pi$ type, describing the internal motions of the atoms under the bending distortion:

$$
\begin{aligned}
q_{\pi_{g} x} & =\sqrt{\frac{m}{2(M+m)}}\left(x_{O_{1}}-x_{O_{2}}\right)-\sqrt{\frac{M}{2(M+m)}}\left(x_{1}-x_{2}\right), \\
q_{\pi_{g} y} & =\sqrt{\frac{m}{2(M+m)}\left(y_{O_{1}}-y_{O_{2}}\right)-\sqrt{\frac{M}{2(M+m)}}\left(y_{1}-y_{2}\right),} \\
q_{\pi_{u} x} & =\sqrt{\frac{m}{2(M+m)}}\left(x_{O_{1}}+x_{O_{2}}\right)-\sqrt{\frac{M}{2(M+m)}}\left(x_{1}+x_{2}\right), \\
q_{\pi_{u} y} & =\sqrt{\frac{m}{2(M+m)}}\left(y_{O_{1}}+y_{O_{2}}\right)-\sqrt{\frac{M}{2(M+m)}}\left(y_{1}+y_{2}\right),
\end{aligned}
$$


Here the index $\gamma=x, y$ of $q_{\pi \gamma}$ labels the lines of the degenerate representations of the $\pi$ type, $x_{O_{i}}, y_{O_{i}}, x_{\mathrm{j}}$ and $y_{\mathrm{j}}$ are the Cartesian displacements of the atoms of oxygen and hydrogen respectively.

In the optimized planar $\mathrm{C}_{2 \mathrm{v}}$ and $\mathrm{C}_{2 \mathrm{~h}}$ geometries there are out-of-plane vibrations ( $\mathbf{a}_{2}$ type in configuration of the $\mathrm{C}_{2 \mathrm{v}}$ symmetry and $\mathrm{a}_{\mathrm{u}}$ type in the $\mathrm{C}_{2 \mathrm{~h}}$ one) which lead to the final "skewed" anticline shape of the $\mathrm{C}_{2}$ symmetry (Fig.1, c, d). Corresponding symmetrized coordinates are:

$$
q_{a_{2}}=\frac{1}{\sqrt{2}}\left(y_{1}-y_{2}\right), \quad q_{a_{u}}=\frac{1}{\sqrt{2}}\left(y_{1}+y_{2}\right)
$$

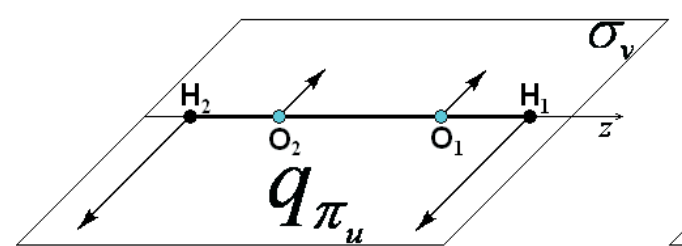

a. $D_{c h h} \rightarrow C_{2 v}$

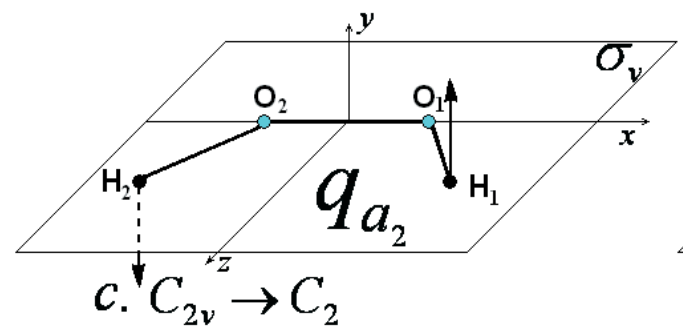

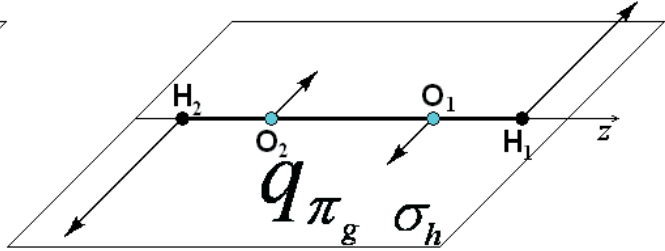

b. $D_{\infty h} \rightarrow C_{2 h}$

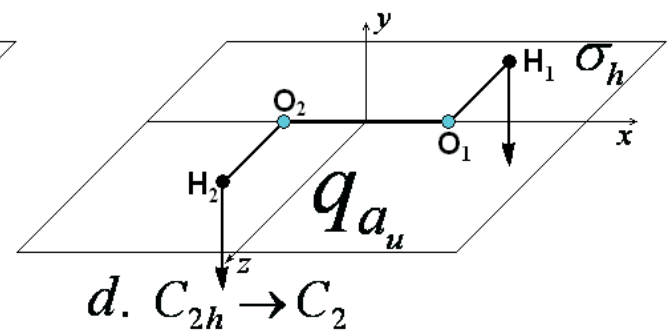

Fig.1. The coordinate axes and atomic numeration for the $\mathrm{H}_{2} \mathrm{O}_{2}$ molecule. The arrows schematically show the displacements active in the PJTE: $\pi_{\mathrm{u}}(\mathrm{a})$ and $\pi_{\mathrm{g}}$ (b) types in the $\mathrm{D}_{\text {oh }}$ configuration, and $\mathrm{a}_{2}(\mathrm{c})$ and $\mathrm{a}_{\mathrm{u}}(\mathrm{d})$ modes in the $\mathrm{C}_{2 \mathrm{v}}$ and $\mathrm{C}_{2 \mathrm{~h}}$ symmetries respectively.

In accordance with the remark in Section 2, the vibronic contribution to the curvature of AP that can lead to the instability of the high-symmetry nuclear configurations come from the vibronic mixing of only those many-electronic states, ground $\Gamma$ and excited $\Gamma^{\prime}$, for which $\Gamma \otimes \Gamma^{\prime}$ contains $\Pi_{\mathrm{u}}$ or $\pi_{\mathrm{g}}$ representations of the $\mathrm{D}_{\infty \mathrm{h}}$ point symmetry group (linear geometry), and $\mathrm{A}_{2}\left(\mathrm{C}_{2 \mathrm{v}}\right)$ and $\mathrm{A}_{\mathrm{u}}\left(\mathrm{C}_{2 \mathrm{~h}}\right)$ representations in corresponding bending configurations.

\section{Electronic structure of hydrogen peroxide $\mathrm{H}_{2} \mathrm{O}_{2}$}

The geometry parameters of the hydrogen peroxide $\mathrm{H}_{2} \mathrm{O}_{2}$ in the linear $\left(\mathrm{D}_{\text {och }}\right)$, planar bent $\left(\mathrm{C}_{2 \mathrm{~h}}\right.$ and $\left.\mathrm{C}_{2 \mathrm{v}}\right)$ and "skewed" anticline $\left(\mathrm{C}_{2}\right)$ nuclear configurations were optimized by ab initio SCF method in the RHF approximation with the use of the extended basis set of the TZV type augmented by polarization d- and f-functions on the oxygen atoms and p-functions on the hydrogen ones. Further the electronic energetic spectrum of the $\mathrm{H}_{2} \mathrm{O}_{2}$ molecule in all the optimized symmetrical geometries was calculated using the configuration interaction (CI) approximation. The active space of CI included seven occupied and three lower unoccupied molecular orbitals. All calculations were performed using the PC GAMESS version [10] of the GAMESS (US) QC package [11].

Calculated parameters of the geometrical structure for all considered symmetrical configurations of the $\mathrm{H}_{2} \mathrm{O}_{2}$ molecule and the values of the total and relative energies of the states are presented in Table 1.

Note that in all the cases not all obtained excited states are listed in Table 1, but only those that give the predominant contribution to the pseudo Jahn-Teller instability (negative force constant) of the ground state. 
Table 1

Optimized geometries $(\AA)$, total energies (hartree), relative energies (e $V$ ) and electronic configurations of the ground and low-lying excited states for symmetry nuclear configurations

\begin{tabular}{|c|c|c|c|c|c|}
\hline Symmetry & Geometry & State & Total energy & $\begin{array}{c}\text { Relative } \\
\text { energy }\end{array}$ & Electronic configuration \\
\hline $\mathrm{D}_{\infty \mathrm{h}}$ & $\begin{array}{l}R_{\mathrm{O}-\mathrm{O}}=1.30 \\
R_{\mathrm{O}-\mathrm{H}}=0.94\end{array}$ & $\begin{array}{l}\sum_{\mathrm{g}}^{+} \\
\prod_{\mathrm{u}}^{\mathrm{g}} \\
\prod_{\mathrm{g}}\end{array}$ & $\begin{array}{l}-150.6219 \\
-150.4905 \\
-150.3415\end{array}$ & $\begin{array}{c}0 \\
3.57 \\
7.63\end{array}$ & $\begin{array}{l}{\left[\ldots\left(\pi_{\mathrm{u}}\right)^{4}\left(\pi_{\mathrm{g}}\right)^{4}\left(\sigma_{\mathrm{u}}\right)^{0}\left(\sigma_{\mathrm{g}}\right)^{0}\right]} \\
{\left[\ldots\left(\pi_{\mathrm{u}}\right)^{4}\left(\pi_{\mathrm{g}}\right)^{3}\left(\sigma_{\mathrm{u}}\right)^{1}\left(\sigma_{\mathrm{g}}\right)^{0}\right]} \\
{\left[\ldots\left(\pi_{\mathrm{u}}\right)^{4}\left(\pi_{\mathrm{g}}\right)^{3}\left(\sigma_{\mathrm{u}}\right)^{0}\left(\sigma_{\mathrm{g}}\right)^{1}\right]}\end{array}$ \\
\hline $\mathrm{C}_{2 \mathrm{~h}}$ & $\begin{aligned} R_{\mathrm{O}-\mathrm{O}} & =1.39 \\
R_{\mathrm{O}-\mathrm{H}} & =0.94 \\
\angle \mathrm{HOO} & =101.6^{\circ}\end{aligned}$ & $\begin{array}{l}A_{g} \\
A_{u}\end{array}$ & $\begin{array}{l}-150.8533 \\
-150.5966\end{array}$ & $\begin{array}{c}0 \\
6.98\end{array}$ & $\begin{array}{l}{\left[\ldots\left(a_{g}\right)^{2}\left(b_{g}\right)^{2}\left(b_{u}\right)^{0}\left(a_{g}\right)^{0}\right]} \\
{\left[\ldots\left(a_{g}\right)^{2}\left(b_{g}\right)^{1}\left(b_{u}\right)^{1}\left(a_{g}\right)^{0}\right]}\end{array}$ \\
\hline $\mathrm{C}_{2 \mathrm{v}}$ & $\begin{array}{c}R_{\mathrm{O}-\mathrm{O}}=1.39 \\
R_{\mathrm{O}-\mathrm{H}}=0.94 \\
\angle \mathrm{HOO}=107.3^{\circ}\end{array}$ & $\begin{array}{l}A_{1} \\
A_{2}\end{array}$ & $\begin{array}{l}-150.8496 \\
-150.5872\end{array}$ & $\begin{array}{c}0 \\
7.14\end{array}$ & $\begin{array}{l}{\left[\ldots\left(b_{2}\right)^{2}\left(a_{2}\right)^{2}\left(a_{1}\right)^{0}\left(b_{2}\right)^{0}\right]} \\
{\left[\ldots\left(b_{2}\right)^{2}\left(a_{2}\right)^{1}\left(a_{1}\right)^{1}\left(b_{2}\right)^{0}\right]}\end{array}$ \\
\hline $\mathrm{C}_{2}{ }^{a}$ & $\begin{array}{c}R_{\mathrm{O}-\mathrm{O}}=1.39 \\
R_{\mathrm{O}-\mathrm{H}}=0.94 \\
\angle \mathrm{HOO}=103.2^{\circ} \\
\varphi_{\text {dihedral }}=110.2^{\circ}\end{array}$ & $A$ & -150.8595 & 0 & {$\left[\ldots(a)^{2}(b)^{2}(a)^{0}(b)^{0}\right]$} \\
\hline
\end{tabular}

${ }^{a}$ Experimental values of the angles: $\angle \mathrm{HOO}=94.8^{\circ}, \varphi_{\mathrm{HOOH}}=111.5^{\circ}[1]$.

The scheme of the electronic terms is shown in Fig. 2, where the dashed lines indicate the alteration of the states under the vibronically stabilized distortions. It is seen that in the high-symmetry linear $\left({ }_{\text {Doh }}\right)$ nuclear configuration the system has a nondegenerate ground state ${ }^{1} \Sigma_{\mathrm{g}}^{+}$, and two low-lying two-fold degenerate ${ }^{1} \Pi_{\mathrm{u}}$ and ${ }^{1} \pi_{\mathrm{g}}$ excited electronic states. As was

mentioned in the previous Section, only the vibronic constants of the type $F_{\pi_{u}}=\left\langle\Sigma_{g}^{+}\left|\left(\partial \hat{H}(r, q) / \partial q_{\pi_{u}}\right)_{0}\right| \Pi_{u}\right.$ and $F_{\pi_{g}}=\left\langle\Sigma_{g}^{+}\left|\left(\partial \hat{H}(r, q) / \partial q_{\pi_{g}}\right)_{0}\right| \Pi_{g}\right\rangle$, and hence only the vibronic contribution to the curvature of the adiabatic potential $K_{\pi_{u}}^{v}$ and $K_{\pi_{g}}^{v}$ are nonzero. If these values are large enough, the linear configuration is unstable with respect to $\pi_{\mathrm{u}}$ and $\pi_{\mathrm{g}}$ types nuclear displacements, and the system passes to more stable cis- $\left(\mathrm{C}_{2 \mathrm{v}}\right)$ or trans- $\left(\mathrm{C}_{2 \mathrm{~h}}\right)$ nuclear configurations. In their turn due to the pseudo JT coupling of the ground ${ }^{1} \mathrm{~A}_{\mathrm{g}}\left(\mathrm{C}_{2 \mathrm{~h}}\right)$ or ${ }^{1} \mathrm{~A}_{1}\left(\mathrm{C}_{2 \mathrm{v}}\right)$ and excited ${ }^{1} \mathrm{~A}_{\mathrm{u}}\left(\right.$ or $\left.{ }^{1} \mathrm{~A}_{2}\right)$

electronic states (i.e. non-zero $F_{a_{u}}=\left\langle A_{g}\left|\left(\partial \hat{H}(r, q) / \partial q_{a_{u}}\right)_{0}\right| A_{u}\right\rangle$ and $F_{a_{2}}=\left\langle A_{1}\left|\left(\partial \hat{H}(r, q) / \partial q_{a_{2}}\right)_{0}\right| A_{2}\right.$ vibronic constants) these bent shapes become unstable with respect to the out-of-plane $\left(a_{u}\right.$ or $a_{2}$ type) displacements of the hydrogen atoms resulting in the equilibrium "skewed" anticline configuration of the $\mathrm{C}$, symmetry.

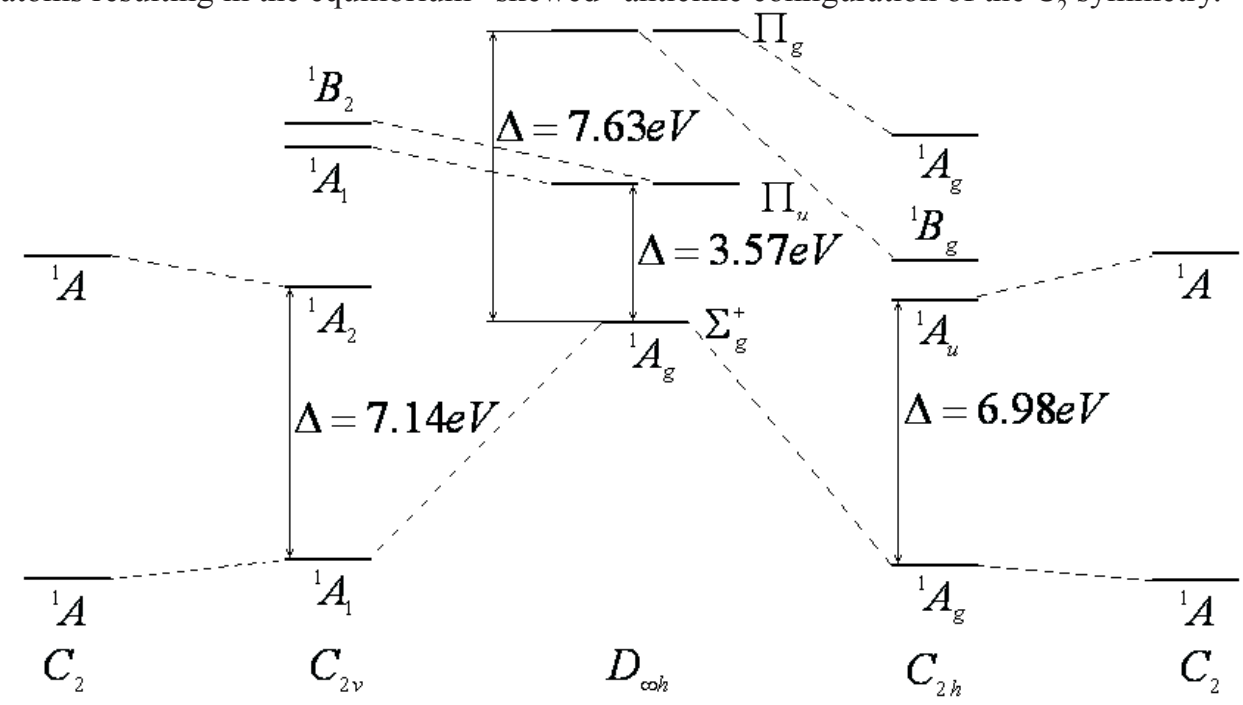

Fig. 2. Eelectronic terms of the $\mathrm{H}_{2} \mathrm{O}_{2}$ molecule in four symmetry configurations 
Consider in more detail the nature of the mixing states. In the linear configuration the first excited $\Pi_{u}$ term arises from the excitation of one electron from the fully occupied $\pi_{\mathrm{g}}$ molecular orbital (formed almost solely from the $2 p_{\pi}$ AOs of the oxygen atoms) to the unoccupied $\sigma_{\mathrm{u}} \mathrm{MO}$ which is an antisymmetrical linear combination of the $2 p_{\sigma} \mathrm{AOs}$ of

the oxygen atoms and $1 s$ AOs of hydrogens. The second excited $\Pi_{g}$ state is formed by one-electron excitation from the same occupied $\pi_{\mathrm{g}} \mathrm{MO}$ to the virtual $\boldsymbol{\sigma}_{\mathrm{g}}$ one which is a symmetrized linear combination of the $2 p_{\sigma}$ AOs of the $\mathrm{O}$ atoms and $1 s \mathrm{AOs}$ of the $\mathrm{H}$ atoms (Table 1 and Fig. 3). Thus the determinants in the CI wavefunctions of the ground $\Sigma_{\mathrm{g}}{ }^{+}$and corresponding excited $\Pi_{\mathrm{u}}$ and $\Pi_{\mathrm{g}}$ electronic states differ by one spin-orbital only. Taking into account that the

Hamiltonian $\boldsymbol{H}$ in eq. 4 is a sum of one-particle operators, the vibronic constants $F_{\pi_{u}}$ and $F_{\pi_{g}}$ can be calculated as one-electron matrix elements of the type $\left\langle\pi_{g} x\left|\left(\partial \hat{H}(r, q) / \partial q_{\pi_{u} x}\right)_{0}\right| \sigma_{u}\right\rangle$ and $\left\langle\pi_{g} x\left(\partial H / \partial q_{\pi_{g} x}\right)_{0} \mid \sigma_{g}\right\rangle$. For the planar bent $\mathrm{C}_{2 \mathrm{~h}}$ and $\mathrm{C}_{2 \mathrm{v}}$ configurations corresponding vibronic constants $F_{a_{u}}=\left\langle A_{g}\left|\left(\partial \hat{H}(r, q) / \partial q_{a_{u}}\right)_{0}\right| A_{u}\right\rangle$ and $F_{a_{2}}=\left\langle A_{1}\left|\left(\partial \hat{H}(r, q) / \partial q_{a_{2}}\right)_{0}\right| A_{2}\right\rangle$ are reduced to the matrix elements $\left\langle b_{g}\left|\left(\partial \hat{H}(r, q) / \partial q_{a_{u}}\right)_{0}\right| b_{u}\right\rangle$ and $\left.a_{2}\left|\left(\partial \hat{H}(r, q) / \partial q_{a_{2}}\right)_{0}\right| a_{1}\right\rangle$ respectively.

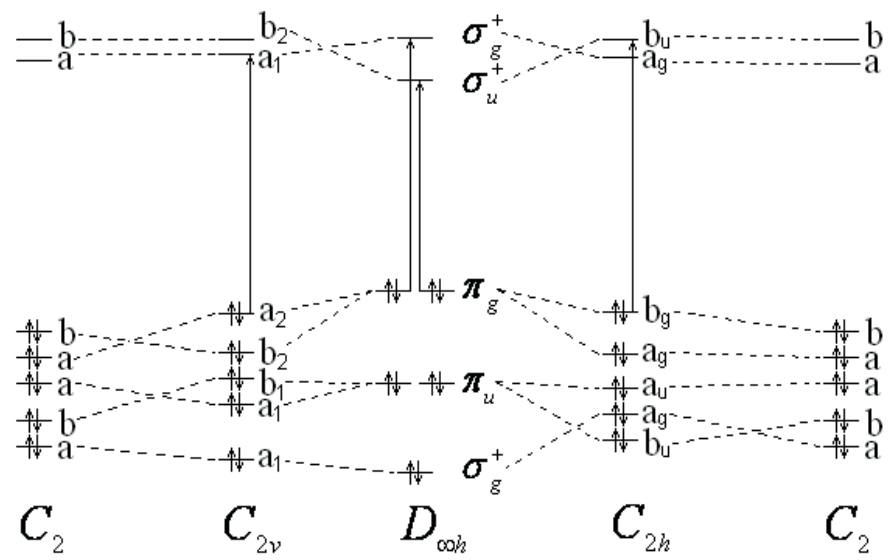

Fig. 3. MO energy level scheme for the $\mathrm{H}_{2} \mathrm{O}_{2}$ molecule in linear $($ Doh $)$, bent $\left(\right.$ cis- $\mathrm{C}_{2 \mathrm{v}}$ and trans $\left.-\mathrm{C}_{2 \mathrm{~h}}\right)$ and equilibrium "skewed" anticline $\left(\mathrm{C}_{2}\right)$ nuclear configurations

The large values of the vibronic constants are due to the nature of the mixing MOs determining the essential changes of the binding by the distortion. Indeed, for example, in the linear configuration the overlap of the occupied $\pi_{\mathrm{g}}$ and unoccupied $\boldsymbol{\sigma}_{\mathrm{u}}\left(\boldsymbol{\sigma}_{\mathrm{g}}\right)$ orbitals is zero by symmetry restrictions (Fig. 4), and hence these orbitals do not contribute to oxygen-hydrogen bonding. Under the $\pi_{\mathrm{g}}\left(\pi_{\mathrm{u}}\right)$ type nuclear displacements the $\pi_{\mathrm{g}} \mathrm{MO}$ split and one of its component become of the same symmetry as the respective admixing virtual orbital. Now their overlap is nonzero resulting in the additional bonding of the $2 p_{\pi}$ AOs of the oxygen atoms with the orbital of the nearest hydrogen atom.

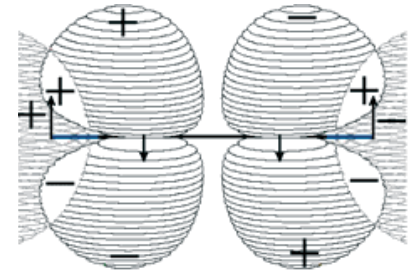

(a)

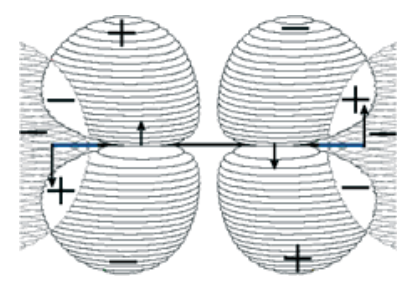

(b)

Fig. 4. Schematic illustration to the covalence origin of the vibronic instability of the linear configuration of $\mathrm{H}_{2} \mathrm{O}_{2}$ : (a) $\pi_{\mathrm{g}} \otimes \sigma_{\mathrm{u}},(\mathrm{b}) \infty_{\mathrm{g}} \otimes \sigma_{\mathrm{g}}$. The overlap integral between the vibronically mixing molecular orbitals (white areas) is zero in the linear $\mathrm{D}_{\infty \mathrm{h}}$ configuration and becomes nonzero by $\pi_{\mathrm{g}}\left(\pi_{\mathrm{u}}\right)$ distortions bending the $\mathrm{H}_{2} \mathrm{O}_{2}$ molecule towards to the cis- $\mathrm{C}_{2 \mathrm{v}}$ (a) and trans $-\mathrm{C}_{2 \mathrm{~h}}$ (b) transition states. 


\section{Numerical calculations of the adiabatic potential}

Potential energy curves of the $\mathrm{H}_{2} \mathrm{O}_{2}$ for all considered displacements $q \bar{\Gamma}\left(\bar{\Gamma}=\pi_{g}, \pi_{u}, a_{u}, a_{2}\right)$ (Fig. 1) were calculated with the ab initio SCF CI method described in Section 3. Fig. 5 show corresponding cross sections of the

APES along the coordinates $q \bar{\Gamma}$. In the starting linear $\left(\mathrm{D}_{\infty \mathrm{h}}\right)$ nuclear configuration $\left(q_{\pi_{g}}=0, q_{\pi_{u}}=0\right)$, as mentioned above, the electronic ground state is ${ }^{1} \Sigma_{\mathrm{g}}^{+}$, and there are two double-degenerate ${ }^{1} \Pi_{\mathrm{u}}$ (at $3.57 \mathrm{eV}$ above the ground state) and ${ }^{1} \pi_{\mathrm{g}}$ (at $7.63 \mathrm{eV}$ ) excited electronic states. Along $q_{\pi_{g}} \neq 0 \quad$ (Fig.4, a) or $q_{\pi_{u}} \neq 0 \quad$ (Fig.4, b) the $\mathrm{D}_{\infty \mathrm{h}}$ symmetry is reduced to $\mathrm{C}_{2 \mathrm{~h}}\left(\mathrm{C}_{2 \mathrm{v}}\right)$ the $\pi_{\mathrm{g}}\left(\Pi_{\mathrm{u}}\right)$ doublets split and one of their components $\left(\mathrm{A}_{\mathrm{g}}\right.$ in $\mathrm{C}_{2 \mathrm{~h}}$ and $\mathrm{A}_{1}$ in $\mathrm{C}_{2 \mathrm{v}}$ configuration) has the strong vibronic admixture to the ground state (due to the relatively large vibronic constants) resulting in the instability of the later with respect to trans- and cis- bending.

Planes $(c)$ and $(d)$ in Fig. 5 represent the cross sections of the APES along the out-of-plane displacements of the hydrogen atoms $\left(\mathbf{a}_{\mathbf{u}}\right.$ or $\mathbf{a}_{\mathbf{2}}$ type) when starting from the $\mathrm{C}_{2 \mathrm{~h}}$ or $\mathrm{C}_{2 \mathrm{v}}$ configurations. In these cases due to the pseudo JT admixture of the excited ${ }^{1} \mathrm{~A}_{\mathrm{u}}\left(\mathrm{C}_{2 \mathrm{~h}}\right)$ or ${ }^{1} \mathrm{~A}_{2}\left(\mathrm{C}_{2 \mathrm{v}}\right)$ terms (Fig.2) the ground electronic ${ }^{1} \mathrm{~A}_{\mathrm{g}}$ ( or ${ }^{1} \mathrm{~A}_{1}$ ) states become unstable with respect to these out-of-plane displacements of the hydrogen atoms. The energies of stabilization are equal to 0.17 $\mathrm{kcal} / \mathrm{mole}$ in the case of $\mathrm{C}_{2 \mathrm{~h}} \square \mathrm{C}_{2}$ distortion and $0.27 \mathrm{kcal} / \mathrm{mole}$ in the $\mathrm{C}_{2 \mathrm{v}} \square \mathrm{C}_{2}$ case.

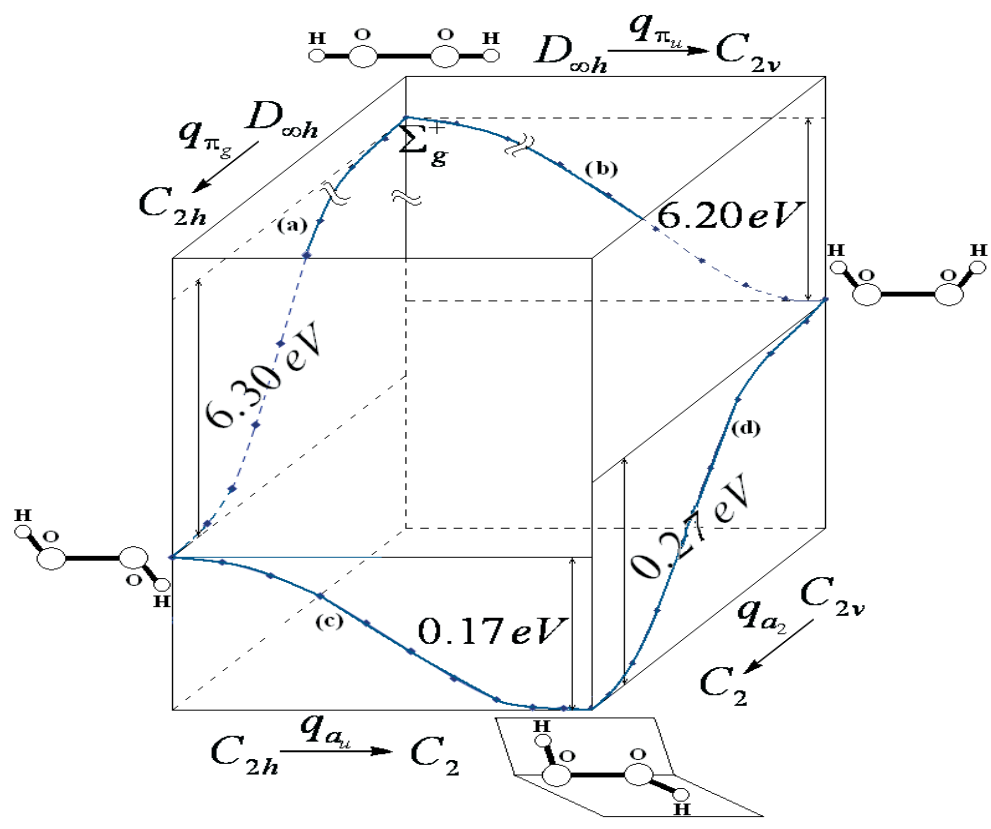

Fig.5. Four cross-sections of the APES of the hydrogen peroxide along: $q_{\pi_{u}}\left(\mathrm{D}_{\infty \mathrm{h}} \square \mathrm{C}_{2 \mathrm{v}}\right)$,

$$
q_{\pi_{g}}\left(\mathrm{D}_{\infty \mathrm{h}} \square \mathrm{C}_{2 \mathrm{~h}}\right), q_{a_{2}}\left(\mathrm{C}_{2 \mathrm{v}} \square \mathrm{C}_{2}\right) \text { and } q_{a_{u}}\left(\mathrm{C}_{2 \mathrm{~h}} \square \mathrm{C}_{2}\right) \text { coordinates. }
$$

We used eq. (1) to estimate the parameters of the vibronic coupling by fitting ab initio data for the APES to the general formulas. The values of parameters of the PJTE, $K_{0}, V$ and $K$, obtained in this way are presented in Table 2.

Table 2

Values of the parameters of the PJT coupling, $K_{0}, V$ and $K$

\begin{tabular}{|c|c|c|c|c|c|}
\hline$q_{\Gamma}$ & $\Delta_{\Gamma}(\mathrm{eV})$ & $\Delta E_{\mathrm{PJT}}(\mathrm{e} V)$ & $K_{0}^{\Gamma}\left(\mathrm{e} V / \AA^{2}\right)$ & $V_{\Gamma}(\mathrm{e} V / \AA)$ & $K_{\Gamma}\left(\mathrm{e} V / \AA^{2}\right)$ \\
\hline$q_{\pi_{g}}\left(\mathrm{D}_{\infty \mathrm{h}} \rightarrow \mathrm{C}_{2 \mathrm{~h}}\right)$ & 7.63 & 6.30 & 3.05 & 6.83 & -9.18 \\
\hline$q_{\pi_{u}}\left(\mathrm{D}_{\infty \mathrm{h}} \rightarrow \mathrm{C}_{2 \mathrm{v}}\right)$ & 3.57 & 6.20 & 2.28 & 6.29 & -19.88 \\
\hline$q_{a_{u}}\left(\mathrm{C}_{2 \mathrm{~h}} \mathrm{C}_{2}\right)$ & 6.98 & 0.17 & 4.09 & 4.25 & -1.09 \\
\hline$q_{a_{2}}\left(\mathrm{C}_{2 \mathrm{v}} \mathrm{C}_{2}\right)$ & 7.14 & 0.27 & 4.26 & 4.43 & -1.24 \\
\hline
\end{tabular}


It is seen from the Table 2, that the values of $\mathrm{K}_{\Gamma}=\mathrm{K}_{0}{ }^{\Gamma}-2 \mathrm{~V}_{\Gamma}{ }^{2} / \Delta_{\Gamma}$ (the curvature of the adiabatic potential) in all these geometries are negative. This confirms that all symmetrical forms $\left(\mathrm{D}_{\infty \mathrm{h}}, \mathrm{C}_{2 \mathrm{~h}}\right.$ and $\left.\mathrm{C}_{2 \mathrm{v}}\right)$ of the hydrogen peroxide molecule $\mathrm{H}_{2} \mathrm{O}_{2}$ are energetically unstable due to the PJT effect. Both transition paths from the $\mathrm{D}_{\infty \mathrm{h}}$ to $\mathrm{C}_{2}\left(\mathrm{D}_{\infty \mathrm{h}} \rightarrow \mathrm{C}_{2 \mathrm{~h}} \rightarrow \mathrm{C}_{2}\right.$ and $\mathrm{D}_{\infty \mathrm{h}} \rightarrow \mathrm{C}_{2 \mathrm{v}} \rightarrow \mathrm{C}_{2}$ ) have the same energetic effect: $\sim 6.47 \mathrm{eV}$.

Note, that the energy gaps between the mixing ground and excited electronic states are rather large in all the cases. However, the vibronic coupling is much larger producing at first one of the planar bent configurations and then the stable "skewed" anticline shape of the hydrogen peroxide. Note also that more sophisticated methods of calculations can give more precise values of the total energies, but they do not change the qualitative details of the rearrangement of molecular orbitals and the formation of new covalent bonds in the system by distortion.

\section{Conclusion}

On the base of the ab initio calculations of the electronic structure and the potential energy surfaces it was shown that the $\mathrm{H}_{2} \mathrm{O}_{2}$ molecule is unstable in both the linear nuclear configuration of the $\mathrm{D}_{\infty \mathrm{h}}$ symmetry and $\backslash$ planar bent cis$\left(\mathrm{C}_{2 \mathrm{v}}\right)$ or trans- $\left(\mathrm{C}_{2 \mathrm{~h}}\right)$ shapes. By fitting of the equation $(1)$ obtained from the vibronic theory to the ab initio calculated hydrogen peroxide APES it is shown that the origin of the instability of these configurations is the pseudo Jahn-Teller effect. The equilibrium "skewed" anticline shape of the $\mathrm{C}_{2}$ symmetry can be realized in two ways: $\mathrm{D}_{\infty \mathrm{h}} \rightarrow \mathrm{C}_{2 \mathrm{v}} \rightarrow \mathrm{C}_{2}$ or $\mathrm{D}_{\infty \mathrm{h}} \rightarrow \mathrm{C}_{2 \mathrm{~h}} \rightarrow \mathrm{C}_{2}$ with decreasing adiabatic potential energy at every step.

\section{References}

[1] Koput J., J. Mol. Spectrosc., 1986, 115, 438-441.

[2] I. B. Bersuker, The Jahn-Teller Effect, Cambridge University Press, Cambridge, England, 2006.

[3] I. B. Bersuker, N.N.Gorinchoi, V.Z.Polinger, Theor. Chim. Acta, 1984, 66, 161.

[4] V.Z.Polinger, N.N.Gorinchoi and I.B.Bersuker, Chem. Phys., 1992, 159, 75-87.

[5] N.N.Gorinchoi, F.Cimpoesu, I.B.Bersuker, J. Mol. Struct. (Theochem), 2001, 530, 281-290.

[6] I.Ogurtsov, N.Gorinchoy, I.Balan, J. Mol. Struct., 2007, 838, 107-111.

[7] J.E.Carpenter and F.Weinhold, J. Phys. Chem., 1988, 92, 4295-4306.

[8] R.Block and L.Jansen, J. Chem. Phys., 1985, 82, 3322-3328.

[9] T.H.Dunning, Jr., N.W.Winter, J. Chem. Phys., 1975, 63, 1847-1855.

[10] Alex A. Granovsky, www http://classic.chem.msu.su/gran/gamess/index.html

[11] M.W.Schmidt, K.K.Baldridge, J.A.Boatz, S.T.Elbert, M.S.Gordon, J.H.Jensen, S.Koseki, N.Matsunaga, K.A.Nguyen, S.Su, T.L.Windus, M.Dupuis, J.A.Montgomery, J.Comput.Chem., 1993, 14, 1347-1363. 